\title{
A Three-step BIM Implementation Framework for the SME Contractors
}

\author{
Arman M. Kouch \\ Oulu University of Applied Sciences, Finland \\ arman. kouch@outlook.com
}

\begin{abstract}
Building information modeling (BIM) is quickly booming while the ICT and digitalization are developing. Still, the BIM implementation particularly for the SME (Small and Medium-sized Enterprises) firms like contractors in the building industry is not efficiently recognized and used. In fact, the SMEs mostly recognize BIM as just a tool to create a 3D model and are not aware of the technology, its implementation and challenges. Therefore, the main aim of this study is to introduce BIM, the factors and challenges related to implementing a basic practical adoption model to employ building information modelling technology for the SME contractors by introducing a basic, easy to implement, practical three-step BIM implementation framework, which can potentially increase their competitiveness and profit.
\end{abstract}

Keywords: Building information modeling, BIM implementation framework, the building industry, BIM adoption, SME contractors

\section{$1 \quad$ Background : BIM and its Importance}

A building description system (BDS), as the origin of BIM, was introduced in 1975 [1]. However, building information modeling is known as a process [2], a new technology and methodology that provides accurate data and processes for all the involved stakeholders [3] to manage and employ the data and to benefit from its integration during the building lifecycle [4-6]. BIM can represent two different meanings that should be distinguished. As a product, BIM is a building information model possessing geometrical information and non-geometrical data. On the other hand, BIM as building information modeling is a process/technology/ methodology including the BIM product. BIM as modeling is a transition from the single sequential process method to a multiple parallel method of data integration, distribution, employment and communication to be used for several tasks and activities from the creation to the demolition of buildings throughout building lifecycle.

Regarding employing new technologies, processes and methods, for instance in comparison with the aviation industry, the building industry and particularly the construction sector are late adopters and have not employed new innovative methods or discovered new opportunities as it happens in other industries [8]. The unwillingness behavior to adopt the latest or new technologies has made difficulties for the industry. The outcome is that productivity, efficiency, quality and profit are decreased and waste,

adfa, p. 1, 2011.

(C) Springer-Verlag Berlin Heidelberg 2011 
risk, duplicating activities and repeating mistakes are increased [6-7]. However, due to enormous progress in ICT and digitalization, the industry has started to realize and ask for more data based processes and integrated management that can increase productivity and efficiency not only for the designing phase but also for the execution, operation and maintenance phases. Furthermore, robotics and automation are being recognized more as solution to mass production, quality, time, waste and labors difficulties. Additionally, the NISB report reveals that only in the US capital facility industry the annual cost of insufficient data interoperability is about $\$ 15.8$ billion dollars [11]. The lack of interoperability can increase the total cost of projects up to 3,1\% [5]. Instead, according to the studies [9-10], BIM increases profit of the firms and return on investment (ROI) in comparison with the traditional approach and creates positive impacts on projects [12-13]. On the other hand, although BIM is used for the design phase, it is not fully recognized for the execution phase in the construction sector. Thus, one of the aims of this research is to address the gap for firms who are active in the construction section by introducing the key factors of the BIM implementation framework. This research, as the outcome of the framework, expects faster project delivery, higher quality, less duplicate works in the project level and increasing efficiency of the organization.

\section{Problem Statement}

According to the European Commission, about $90 \%$ of the firms are SMEs, including micro, small and medium-sized enterprises with up to 250 employees and 50 million Euros turnover annually. SMEs create about $67 \%$ of the jobs [17] consequently their role in the industry is significant and should be addressed.

As it was mentioned previously, the technical and financial benefits of BIM are not efficiently achieved by the firms, specially by the SME contractors, because the building industry and the construction sector hesitate to employ BIM [14,16]. Additionally, the SME contractors are mainly not aware of the technology as modelling and the key factors that can increase their competitiveness, profit and even save their existence in the future, the era of automation and robotics. One of the reasons for the hesitation could be that the current frameworks are more focused on the theory and the ontology of BIM, are mostly studied for big companies, providing too many details and might not introduce a simple practical framework, which is suitable for the SME contractors. Thus, the main problem that this study attempts to address is that an effective simple BIM implementation framework tailored for SME contractors is still missing.

\section{$3 \quad$ Methodology}

First, in order to determine an effective BIM implementation framework, this research reviews and extracts the literatures on the BIM implementation challenges and issues as well as the effective factors. The literature review consists of more than a decade of the previous studies on the BIM implementation and relevant topics. A summary of the review is tabulated in Table 1 , followed by the key factors. Then analysis and critical discussions will be provided. In the end, a general practical BIM implementation framework, as a guideline for the SME contractors, will be presented. 


\subsection{Literature Review}

With the aim of improving the processes of design, planning and construction for USACE (the U.S. Army Corps of Engineers), in 2006 a strategic BIM implementation plan was offered by Brucker et al [15]. The plan is based on current design team and assigning a BIM team who is responsible for an action plan. The team members, aims, processes, tasks, metrics and training are the key factors of the implementation plan. However, in 2009 according to the interviews from the UK and Finland, Arayici et al [18] studied the factors, challenges and barriers of the BIM implementation. The survey-based research of the construction stakeholders and academics shows that organizational changes and processes are the two significant factors for the implementation while BIM technology, BIM based tools, training, costs, and unclear BIM's technical \& financial benefits are highly considered. In 2009, Succar [19] created the BIM domain concepts as a BIM ontology. The domain describes the BIM conceptual parts and the main BIM activity fields as technology, process and policy. The fields share players like designers (architectural, structural, mechanical etc.), contractors, technology developers, manufacturers, operators, legal bodies, researchers and owners). They also share some deliverables such as construction services/ products, standards, regulations and equipment (software, hardware). Furthermore in 2010, an interview based research study on focused group of architects, engineers and contractors by Gu and London [20] shows that two main issues of the adoption are technical issues ( BIM tools and software) and non-technical issues (processes, strategies and work practices).

However, in 2011, Jung and Joo [21] introduced a BIM framework based on BIM perspective, technology and business model. The BIM perspective indicates three levels of BIM utilization as in projects, organizations and the industry. The technology includes data and standards. The BIM business function refers to such as design, estimation, planning, scheduling, materials, safety, contracts, cost control, sales, research and developments, HR and administrations. In 2012, Khosrowshahi and Arayici (22) described an extensive BIM implementation roadmap with three main factors on training, organizational culture and information management focused on managerial and operational levels. Besides, in 2013 Eadie et al [12] indicated that BIM could be used in the entire period of building lifecycle and process, stakeholder collaboration, software, BIM experience and training are the most effective factors of the adoption. Furthermore, the study of Takim et al [23] in 2013 revealed that there could be gaps due to process change, technical supports, product limitation, people acceptance, economic demand, profitability, simple methodology and use. Additionally, in 2014, Miettinen and Paavola [24] published an analytical study, which introduces the important factors such as continuous learning, guidelines, standards and local trialing. In 2014, Morlhon et al [25], introduced the BIM implementation factors as standards, external stakeholders, process (business and system), education (management and technical). Meanwhile at the same year, Peter Smith [26] found that, training, business impacts, standards (national and global), legal and liability issues, research and governmental support are the main factor of the implementation. Also, in 2015 Son et al [28] presented the BIM implementation drivers as management support and the computer knowledge in an architectural organization. 
Table 1. Literature review summary

\begin{tabular}{|c|c|c|c|c|c|c|c|}
\hline Fields & Orgar & ization & People & & Process & Technology & Policy \\
\hline $\begin{array}{r}\text { Factors/ equivalnt } \\
\text { parameters }\end{array}$ & $\begin{array}{l}\text { Investment } \\
\text { (costs, ROI) }\end{array}$ & $\begin{array}{l}\text { Risks \& } \\
\text { Challenges }\end{array}$ & $\begin{array}{c}\text { Training \& } \\
\text { need (HR, } \\
\text { organizatioan) }\end{array}$ & $\begin{array}{c}\text { Resistance } \\
\text { to } \\
\text { changee }\end{array}$ & $\begin{array}{c}\text { Work } \\
\text { process \& } \\
\text { team } \\
\text { collaboration }\end{array}$ & $\begin{array}{c}\text { Tools } \\
\text { (software } \\
\& \\
\text { hardware) }\end{array}$ & $\begin{array}{c}\text { Standards, } \\
\text { Regulations } \\
\text {, legal } \\
\text { issues }\end{array}$ \\
\hline Brucker et al, 2006 & & 0 & 0 & & 0 & 0 & \\
\hline Arayici et al, 2009 [18] & 0 & 0 & 0 & 0 & 0 & & \\
\hline Succar, 2009 [19] & & & 0 & & 0 & 0 & 0 \\
\hline Gu and London, 2010 [20] & & 0 & & & 0 & 0 & \\
\hline Azhar, 2011 & 0 & 0 & 0 & 0 & 0 & 0 & 0 \\
\hline Jung and Joo (2011) [21] & 0 & 0 & 0 & & 0 & 0 & 0 \\
\hline Eastman et al, 2011 [7] & 0 & 0 & 0 & 0 & 0 & 0 & 0 \\
\hline $\begin{array}{l}\text { Khosrowshahi and Arayici } \\
(2012)[22]\end{array}$ & 0 & 0 & 0 & 0 & 0 & 0 & 0 \\
\hline Eadie et al (2013) [12] & & & 0 & & 0 & 0 & \\
\hline Takim et al (2013) [23] & 0 & & & 0 & 0 & 0 & \\
\hline $\begin{array}{l}\text { Miettinen and Paavola } \\
\text { (2014) [24] }\end{array}$ & & & $\bigcirc$ & & & & 0 \\
\hline Morlhon et al (2014) [25] & & 0 & 0 & & 0 & & 0 \\
\hline Peter Smith (2014) [26] & 0 & 0 & 0 & & & & 0 \\
\hline $\begin{array}{l}\text { Lindblad and Vass (2015) } \\
\text { [27] }\end{array}$ & & & & & 0 & & \\
\hline Son et al (2015) [28] & & 0 & & & & 0 & \\
\hline Tulenheimo (2015) [29] & 0 & 0 & 0 & 0 & 0 & 0 & \\
\hline Bui et al (2016) [30] & 0 & & 0 & & & & 0 \\
\hline Cao et al (2016) [31] & 0 & 0 & 0 & & & & \\
\hline Hosseini et al (2016) [32] & 0 & 0 & & & & & \\
\hline $\begin{array}{l}\text { Ghaffarianhosein et al } \\
\text { (2017) [14] }\end{array}$ & 0 & 0 & 0 & & 0 & 0 & \\
\hline
\end{tabular}

However, in 2015 the key barriers and challenges for the adoption were studied by Risto Tulenheimo [29]. The results are listed as clients demand, managerial vision and strategy, organizational change process and technology (hardware and software). In 2016, Bui et al [30] mentioned that in developing countries governmental supports, standards, legal issues, BIM knowledge, business function and BIM benefits are the current BIM adoption factors. Furthermore, Cao et al [31] suggested a strong relation between the BIM implementation motivation and organizational ownership as well as its economic benefits during maturing of BIM. Meanwhile, Hosseini et al [32] found that SMEs' lack of interest and higher investment risk are the key factors. Finally, a 2017 study of Ghaffarianhoseini et al [14] on the BIM implementation revealed the 
critical factors such as process development (change), business development (demand and ROI), training (skills and experience) and tools (software and hardware). However, the literature review shows that various viewpoints and approaches were used by different studies to address the factors or the equivalent parameters. The summery of the literature review is illustrated in Table 1 where a group of factors is pointed by each field that addresses the vital requirements, issues and challenges that potentially influence the BIM implementation.

\subsection{Analysis and Discussion}

The literature review verifies a complex nature of the implementation and its broad range of factors as well as their interconnections. In order to build a basic approach of a general practical BIM implementation framework for the SME contractors, this article provides an analysis and discusses common critical issues required for an effective framework. According to Table 1, the most frequently cited factors, indicated in the previous studies, are organization (28 times), people (21 times), process (14) and technology (12 times) followed by policy ( 9 times) respectively. Figure 1 illustrates the fields, the factors and their linear distribution percentages, which, in this text, are also written in the brackets. As it is shown in Figure 1, the fields are divided into two layers

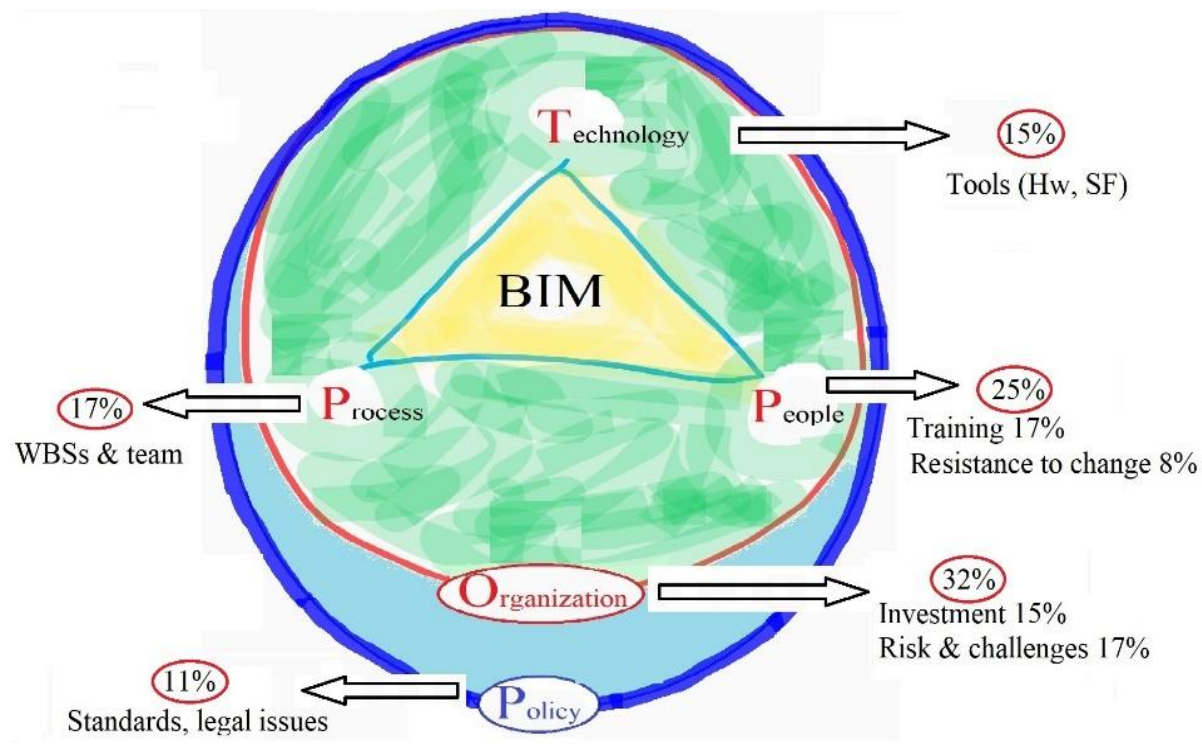

Fig. 1. The BIM implementation key factors and the distribution percentages

as an inner layer (red circle) that includes organization $(32 \%)$ that possesses the major role for the implementation, people (25\%), process (17\%) and technology (15\%) and an outer layer (blue circle) as policy field (11\%). The inner layer reflects a firm's internal domain of actions and reactions. It is affected by its internal stakeholders, processes and tools. The policy field includes e.g. governments who can affect the firms by legal issues and standards. 
This analysis proves the vital role of organization, represented by top managers (plus CEOs \& board members), including the business challenges and risks (17\%) as well as investments and financial factors $(15 \%)$ such as the costs and return on investment (ROI). Therefore, the first step of any adoption should consider the top managers' understanding and strong support, which means only utilizing the technology (e.g. employing software) without a long-term/ strategic plan, might decrease the effectiveness of the adoption or lead to an unsuccessful implementation. The second major field is people, with a major effect of $17 \%$ for training and $8 \%$ for employees' resistance to change, indicating the role of the team members and the related challenges. The third field is process field (17\%), includes work processes and team collaboration, addressing what should be done and how the processes should be managed. The next important field is technology (15\%) that indicates tools, software and hardware that represents all means required for an effective implementation framework. Finally, the external field is policy $(11 \%)$ that reflects standards, mandates, legal issues and guidelines by governments.

Although the studies have covered various viewpoints, so far finding a general basic consolidated implementation model or a simple practical BIM implementation framework is missing. Furthermore, the studies are mostly focused on theoretical and academic view. In fact, the current BIM implementation frameworks might not effectively provide an easy to follow and a simple practical framework that can help a majority of the SME contractors to harvest the benefits of the studies due to being more theoretical or providing a lot of details with advanced knowledge. Thus, an easy to implement basic approach of the BIM adoption that can almost cover all known aspects and challenges for the practitioners, particularly the SME contractors is required. Actually, this proposed BIM implementation framework systematically attempts to address all the factors and challenges in an effective simplistic and considerably practical model to provide better implementation than the current models.

\section{$4 \quad$ Implementation Framework}

A general 3-step BIM implementation framework, which can satisfy all mentioned aspects of an effective simple practical implementation framework, is easy to follow and implement is illustrated in Figure 2. As it mentioned earlier, this BIM implementation framework is proposed to be used by SME contractors. However, due to similarities between the other firms in the building industry, such as design or maintenance firms, it is feasible for other enterprises to employ the framework with some modifications in the third step. The framework is a three-step model including understanding (step one), planning (step two) and piloting (step three).

The first step for implementing BIM is an understanding step. This is an important step for the top managerial level like CEOs and boards to learn the impacts, challenges, benefits and opportunities BIM can provide in short-term and long-term for the firms. Defining a new strategy that possibly can target a longer run, exploring business opportunities and more integrated delivery approach are considered. However, part two of the first step is dedicated to directors and other middle level managers to address challenges, legal issues, BIM teams and short-term strategies. 


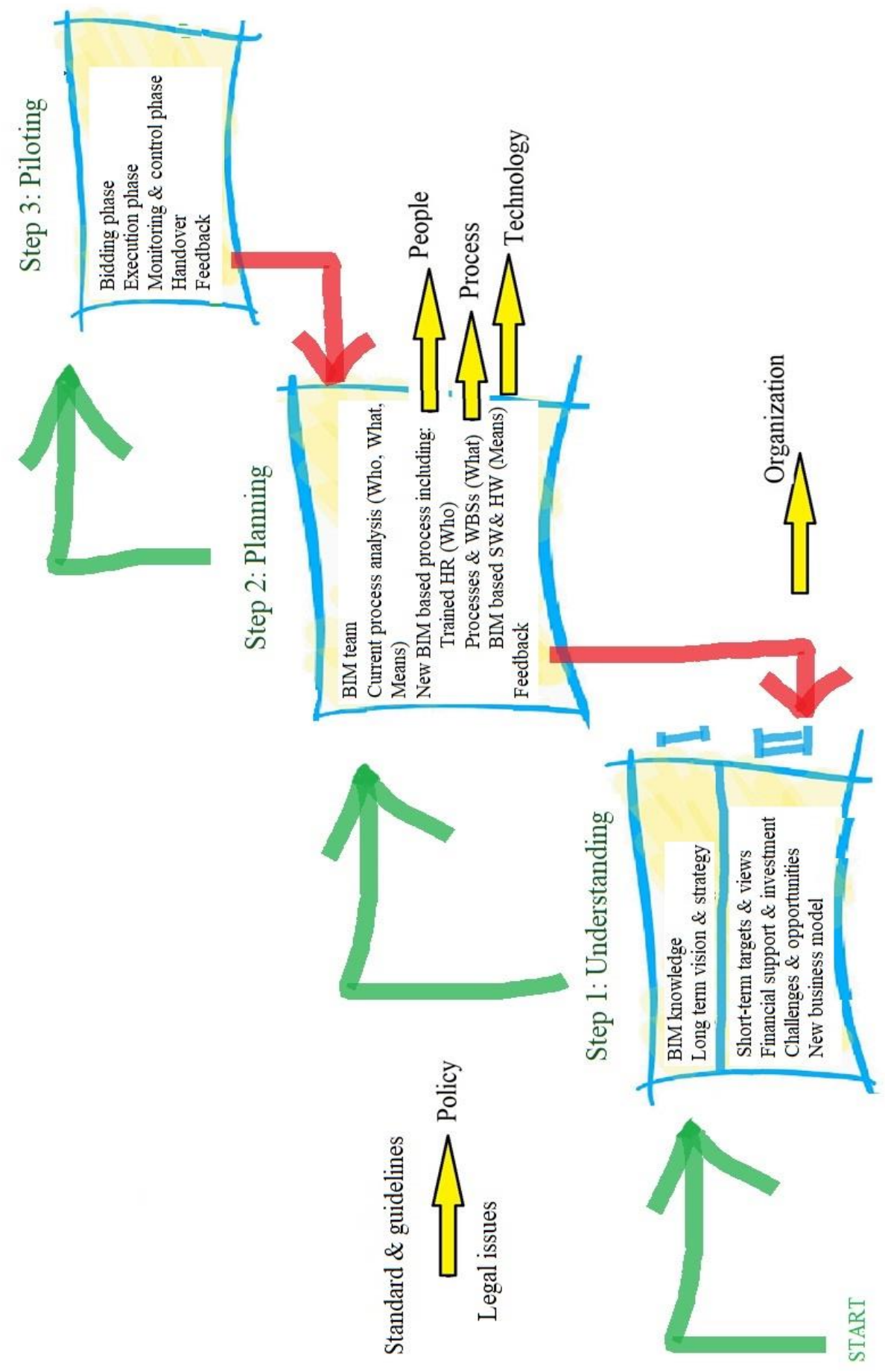

Fig. 2. A general 3-step BIM implementation framework 
The second step is the planning step. In this step, assigned BIM teams including the current teams and BIM experts analyze current activities, processes, tools and resources in order to create a new BIM based approach of the processes. Feedbacks of this step will be transferred to the organizational level to amend the short-term and the long-term strategies as well as to support the processes. Additionally, current standards and guidelines can be used in this step.

The third step is called piloting. In this step what has been planned in step two will be executed. This is a practical step thus tools such as software for preparing QTL (quantity takeoff list) and cost estimation in the bidding phase extracted from 3D models will be used. Also, in this step clash detection and constructability will be examined via appropriate tools in order to decrease the time and increase the accuracy of the execution plans and works besides work activities, scheduling, risk management plans etc. VR (virtual reality) and AR (augmented reality) tools can be employed in this step to assist the execution, monitoring and verification of the activities on sites and off sites. The feedbacks from this step will be sent to the BIM teams in step two for future evaluation of the planning step and make it more efficient. Finally, the circulation of the information, data and knowledge will improve productivity and efficiency of the firms.

\section{Conclusion}

This study has tried to introduce BIM as modelling, the factors and challenges related to implementing an initial framework that can employ BIM technology for the SME contractors. The main aim of this study is to provide a basic and easy to implement BIM implementation framework that is extensively required assisting the SME contractors to harvest the benefits that an effective practical framework can provide. Finally, a three-step BIM implementation framework/ guideline is provided for an effective BIM adoption. This study proposes a future research on the presented framework to be employed for different kind of SME contractors to evaluate the results in real cases.

Acknowledgments. The author would like to thank Jyrki Röpelinen, the director of civil engineering department of Oulu University of Applied Sciences (OAMK) for the financial support and the members of the Interrg Nord project, Increasing Competence in Northern Building (ICNB), from Finland, Norway and Sweden for their contributions during the workshops and the meetings.

\section{References}

1. Eastman, C.M.: The Use of Computers Instead of Drawings in Building Design. AIA Journal, 1(1):46-50 (1975)

2. Penttilä, H.: Describing the changes in architectural information technology to understand design complexity and free-form architectural expression. Journal of Information Technology in Construction (ITcon), 11:395-408 (2006)

3. Woo, J.H.: BIM (Building Information Modeling) and Pedagogical Challenges. In Proceedings of the 43rd ASC National Annual Conference (2006) 
4. Laiserin, J.: To BIMfinity and Beyond! (AEC Insight Column), Building information modeling for today and tomorrow. On-line: http://www.cadalyst.com/aec/to-bimfinity-and-beyond-aec-insight-column-3686, Accessed: 01/09/2017.

5. McGraw-Hill: Interoperability in the Construction Industry, in SmartMarket Report. McGraw Hill Construction (2007)

6. Azhar, S.: Building Information Modeling (BIM): Trends, Benefits, Risks, and Challenges for the AEC Industry. Leadership and Management in Engineering, 11(3):241-252 (2011)

7. Eastman, C., Teicholz, P., Sacks, R., and Liston, K.: BIM Handbook - A Guide to Building Information Modeling for Owners, Managers, Designers, Engineers, and Contractors, 2nd Ed. John Wiley \& Sons, Inc. (2011)

8. Buehler M.: 10 ways aerospace can shape the future of construction. On-line: https://www.weforum.org/agenda/2016/11/future-of-construction-lessons-fromaerospace/, Accessed: 15/01/2017

9. Azhar, S., Hein, M., Sketo, B.: Building Information Modeling (BIM): Benefits, Risks and Challenges. The 44th Associated Schools of Construction National Conference, Auburn, AL (2011)

10. Barlish, K., Sullivan, K.: How to measure the benefits of BIM - A case study approach. Automation in Construction, 24:149-159 (2012)

11. Gallaher, M.P., O’Connor, A.C., Dettbarn, J., John, L., Gilday, L.T.: Cost Analysis of Inadequate Interoperability in the U.S. Capital Facilities Industry. The USA National Institute of Standards and Technology (NIST) ( 2004)

12. Eadie, R., Browne, M., Odeyinka, H., McKeown, C., McNiff, S.: BIM implementation throughout the UK construction project lifecycle: An analysis. Automation in Construction, 36:145-151 (2013)

13. Motawa, I., Almarshad, A.: A knowledge-based BIM system for building maintenance. Automation in Construction, 29:173-182, 2013.

14. Ghaffarianhoseini, A., Tookey, J., Ghaffarianhoseini, A., Naismith, N., Azhar, S., Efimova, O., Raahemifar, K.: Building Information Modelling (BIM) uptake: Clear benefits, understanding its implementation, risks and challenges. Renewable and Sustainable Energy Reviews, 75: 1046-1053 (2017)

15. Brucker, B. A., Case, M. P., East, E. W., Huston, B. K., Nachtigall S. D., Shockley, J. C., Spangler, S. C., Wilson, J. T.: Building Information Modeling (BIM): A Road Map for Implementation To Support MILCON Transformation and Civil Works Projects within the U.S. Army Corps of Engineers. Engineer Research and Development Center, U.S. Army Corps of Engineers (2006)

16. Hosseini, M. R., Banihashemi, S., Chileshe, N., Namzadi, M. O., Udaeja, C., Rameezdeen, R., McCuen, T.: BIM adoption within Australian Small and Medium-sized Enterprises (SMEs): an innovation diffusion model. Construction Economics and Building, 16(3):71 (2016)

17. Europian Commission: User guide to the SME Definition. Luxembourg: Publications Office of the European Union (2015)

18. Arayici , Y., Khosrowshahi, F., Marshal Ponting A., Mihindu S.: Towards implementation of Building Information Modelling in the construction industry, in Fifth International Conference on Construction in the 21st Century (CITC-V). Collaboration and Integration in Engineering, Management and Technology, May 20-22, 
2009, Istanbul, Turkey (2009)

19. Succar, B.: Building information modelling framework: A research and delivery foundation for industry stakeholders. Automation in Construction, 18(3):357-375 (2009)

20. Gu, N., London, K.: Understanding and facilitating BIM adoption in the AEC industry. Automation in Construction, 19(8):988-999 (2010)

21. Jung, Y., Joo, M.: Building information modelling (BIM) framework for practical implementation. Automation in Construction, 20(2):126-133, 2011.

22. Khosrowshahi, F., Arayici, Y.: Roadmap for implementation of BIM in the UK construction industry. Engineering, Construction and Architectural Management, 19(6):610-635 (2012)

23. Takim, R., Harris, M., Nawawi, A.H.: Building Information Modeling (BIM): A New Paradigm for Quality of Life Within Architectural, Engineering and Construction (AEC) Industry. Procedia - Social and Behavioral Sciences, 101: 23-32 (2013)

24. Miettinen, R., Paavola, S.: Beyond the BIM utopia: Approaches to the development and implementation of building information modeling. Automation in Construction, 43: 84-91 (2014)

25. Morlhon, R., Pellerin, R., Bourgault, M.: Building Information Modeling Implementation through Maturity Evaluation and Critical Success Factors Management. Procedia Technology, 16: 1126-1134 (2014)

26. Smith, P.: BIM Implementation - Global Strategies. Procedia Engineering, 85:482-492 (2014)

27. Lindblad, H., Vass, S.: BIM Implementation and Organisational Change: A Case Study of a Large Swedish Public Client. Procedia Economics and Finance, 21: 178-184 (2015)

28. Son, H., Lee, S., Kim, C.: What drives the adoption of building information modeling in design organizations? An empirical investigation of the antecedents affecting architects' behavioral intentions. Automation in Construction, 49:92-99 (2015)

29. Tulenheimo, R.: Challenges of Implementing New Technologies in the World of BIM - Case Study from Construction Engineering Industry in Finland. Procedia Economics and Finance, 21:469-477 (2015)

30. Bui, N., Merschbrock, C., Munkvold, B.E.: A Review of Building Information Modelling for Construction in Developing Countries. Procedia Engineering, 164:487-494 (2016)

31. Cao, D., Li, H., Wang, G., Huang, T.: Identifying and contextualising the motivations for BIM implementation in construction projects: An empirical study in China. International Journal of Project Management, 35: 658-669 (2017)

32. Hosseini, M. R., Namzadi, M. O., Rameezdeen, R., Banihashemi, S. and Chileshe, N.: Barriers to BIM adoption: Perceptions from Australian Small and Mediumsized Enterprises (SMES). In 40th AUBEA 2016 conference, Radical Innovation for Built Environment, 271-280, (2016) 